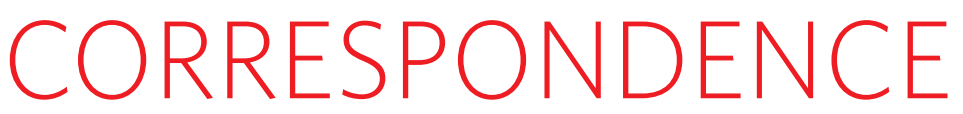

\section{Helping young scientists to speak for themselves}

SIR - As you indicate in your Editorial 'Cheerleader or watchdog?' (Nature 459, 1033; 2009), the quality of science journalism could be improved by better communication between scientists and the media. We should encourage this valuable skill in scientists at the outset.

I help an international team of high-school students to manage an online journal, Young Scientists, which is entirely written by people aged 12-20. To our knowledge, Young Scientists (www.ysjournal.com) is the only peer-reviewed science journal for school-aged students. Articles range from reviews of current hot topics to scholarly pieces of original research.

Many youngsters are now involved in scientific research, and at an increasingly early age - as demonstrated by the proliferation of science fairs around the world. Sadly, communication of all this promising work suffers because, once these bright young scientists have exhibited and gone home, their work goes with them. They need more opportunities to publish and share their ideas - before science journalists who are not scientists try to do their communication for them.

Science journalism is making increasing use of online media, which includes social networking sites. Who better to embrace it than our young scientists? If we can engender in them a critical perspective on the way science is reported and encourage them to participate in the process themselves, then we can look forward to a generation of scientists proficient at weighing up evidence and articulate in communicating it.

Christina Astin Physics Department, The King's School, Canterbury, Kent CT12ES, UK e-mail:cma@kings-school.co.uk

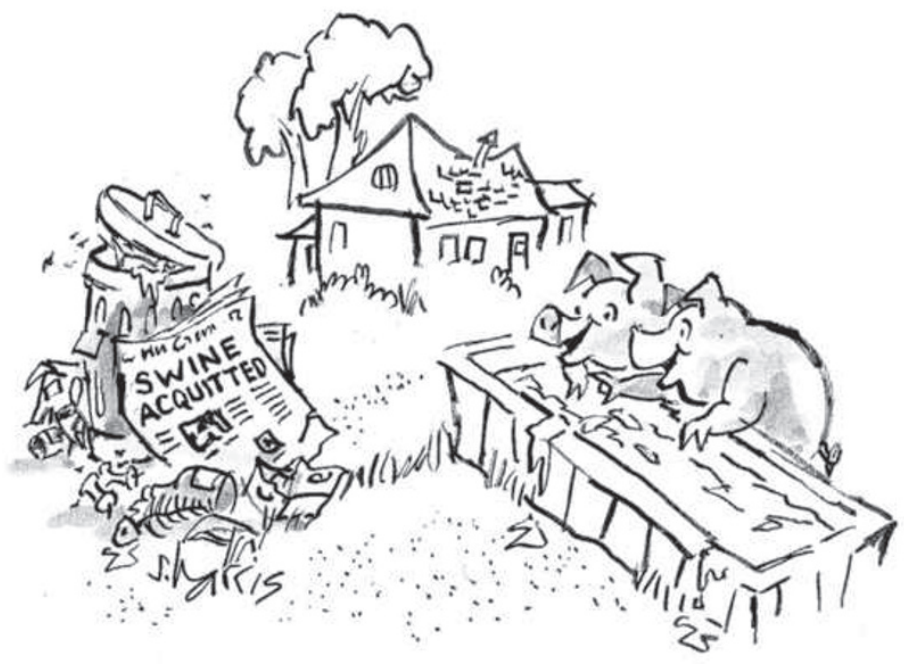

by strengthening veterinary infrastructure and stepping up surveillance and reporting capabilities in all countries, regardless of their trade potential.

Bernard Vallat World Organisation for Animal Health, 12 rue de Prony, 75017 Paris, France e-mail:b.vallat@oie

\section{Small but effective moves towards a greener China}

SIR - Your Editorial 'Raising

the standards' (Nature 459, 1033-1034; 2009) reports on the pressure being imposed by non-governmental organizations on China's local governments to provide the public with more information about pollution. There is encouraging evidence that even a small organization can have an impact in this domain.

Ten years ago, there was hardly any environmental enforcement by civil society or by the markets in China. In 1999-2000, the World Bank collaborated on a pilot programme with the Chinese Academy of Environmental Planning, Nanjing University, the Zhenjiang Environmental Protection Bureau in Jiangsu Province and the Hohhot Academy of Environmental Sciences in Inner Mongolia. This experiment, aimed at publicizing information about environmental performance, was run in Hohhot and Zhenjiang. Although the programme was halted at the end of the pilot phase in Hohhot, it was sustained in Zhenjiang.

Despite the top leadership's intention to clean up China's environment, the evaluation system is biased towards economic development. A push from the bottom is badly needed to attract the attention of local governments to the environment.

The Pollution Information Transparency Index now has wide geographical coverage, and efforts are continuing by the Natural Resources Defense Council 